\title{
Restoration of Pteraspis.
}

My dear Sir,-I have read the Rev. H. Mitchell's paper on "The Restoration of Pteraspis" with great interest, but the conclusions he draws from his Scoteh specimens are, I think, by no means borne out by examples obtained from English localities. I enclose you two sketches of Pteraspids from Cradley, in Herefordshire : one, in my own collection, showing the anterior portion of the shield; the other, exhibiting the posterior portion and surface markings, in the possession of Mr. Gregory, of Golden Square. These two sketches will be sufficient to show that the shield, as drawn by Mr. Mitchell, is wanting in some important particulars; the true form I believe to be that given in fig. 3 . Mr. Mitchell seems to be under the im. pression that the restoration of Pteraspis has never before been attempted, although first-rate specimens have been in our museums and private collections for some years. Professor Huxley, in vol. xvii. of Geol. Soc. Journal, has given a diagram of a restored Pteraspis, which is copied in fig. 3 ; he has likewise referred to the subject in British Association Reports, 1858 , and has further

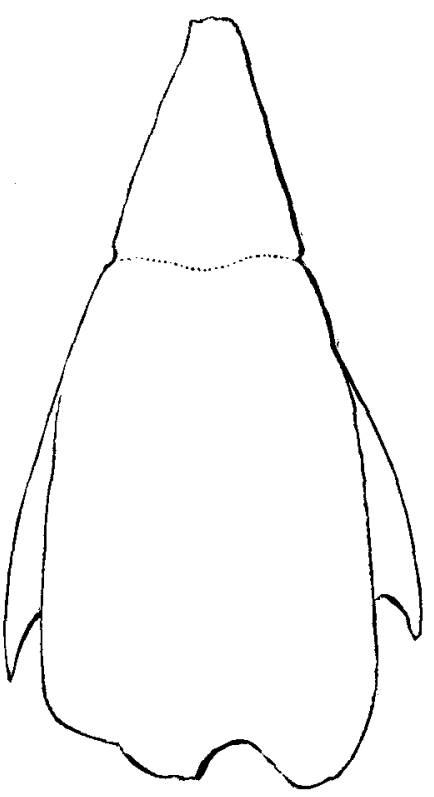

Fig. 1.

written a detailed account of the microscopic structure of the test in vol. xiv. of the Journal. The references in fig. 3 are as follows :- $a$ is the snout or rostrum, united with $b$, the shield-like disk ; $c c$ are the lateral cornua attached to the disk; $e$ is the posterior spine, and $f f$ are the orbits or perhaps the nasal apertures. The corresponding parts can be easily found in the sketches I have given of the fossil Pteraspids. I may just mention here, that the bonelike test of these fish is composed of three layers, - an external, finely striated layer, a middle cancellated layer composed of polygonal cells, and a third internal layer of a laminated nacreous substance. The specimen drawn in fig. 2 shows the external layer remarkably well ; in fig. 1 , parts of the middle cancellated layer may be seen; the rest of the test, which is preserved, being the internal nacreous layer. I remain, dear Sir, yours truly, E. R. LANKESTER.

8, Savile Row, Nov. 9.

P.S.-You will observe some minute indentations drawn in fig. 2 , on the surface

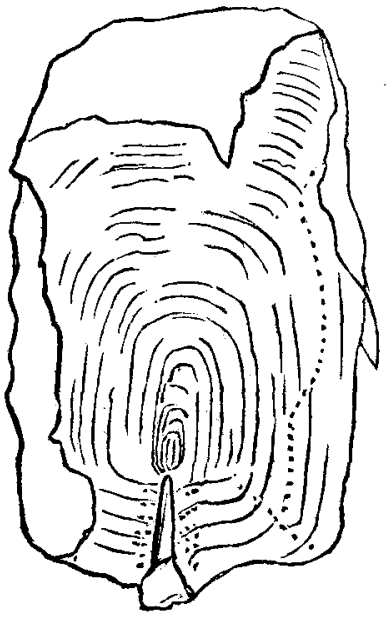

Fig. 2. 


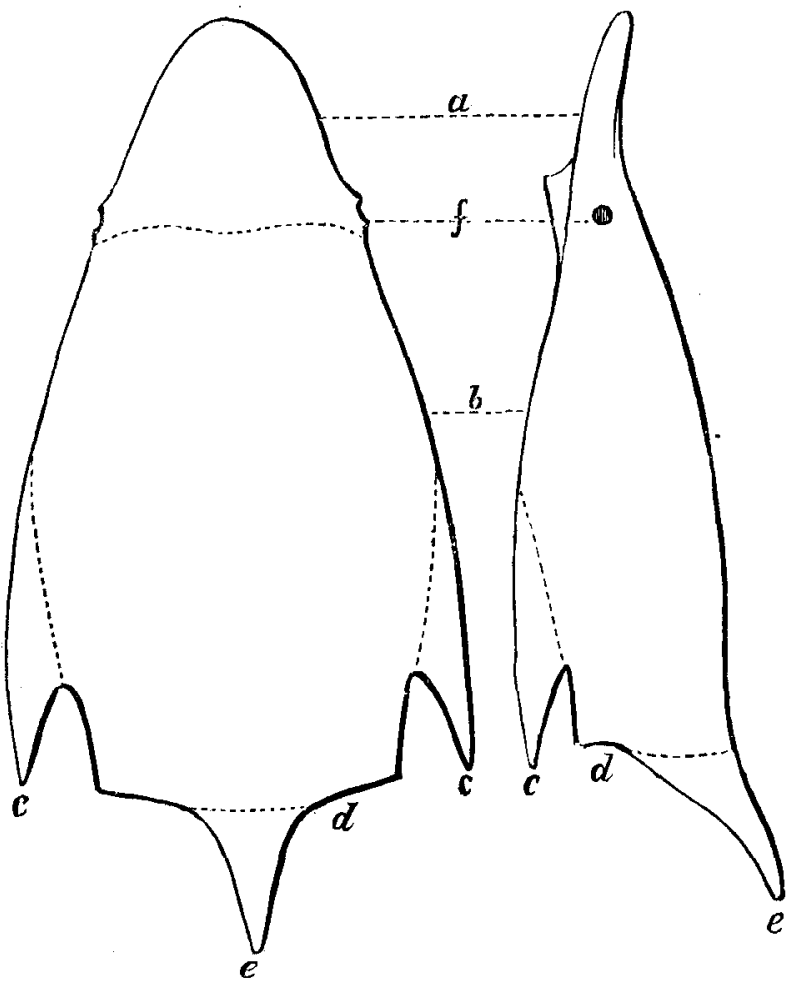

Fig. 3.-Diagram of restored Pteraspis.

of the shield. Professor Huxley informs me that he believes them to be the sites (if I may so say) of mucous follicles. I have thought this worth mentioning in a note, as they have never before been noticed.

\section{When and how was the Isle of Wight severed from the Mainland?}

Sir,- - On two difierent occasions inquiries have been made in the pages of the 'Geologist,' as to the period at which the Isle of Wight was torn from the mainland and entrusted to the rude guardianship of the ocean. The subject is an interesting one, especially in its geological aspects; and as I have given some attention to it, I will attempt to reply to the inquiries of your Lymington correspondent.

I am not aware that there is the least particle of historical evidence that gives countenance to the famous passage in Diodorus Siculus that has been interpreted by various writers as proving that, when he lived, the channel of the Solent was fordable at low water. As the particular island of which Diodorus is speaking, was one from which the miners of Cornwall were in the habit of exporting their minerals, and there is a small isle (St. 